\title{
Aerobic Bacterial Isolates and Their Antibiotic Susceptibility Patterns of Pus Samples at Tertiary Healthcare Center of Northern India
}

\author{
Aditya Rana ${ }^{1}$, Veehteeanveshna Gupta ${ }^{2}$, Subhash Chand Jaryal ${ }^{3}$, \\ Anuradha Sood $^{4}$ \\ ${ }^{1,2} \mathrm{JR}$, Department of Microbiology, DRPGMC Kangra at Tanda. \\ ${ }^{3}$ Professor and Head of the Department, Department of Microbiology, DRPGMC Kangra at Tanda. \\ ${ }^{4}$ Associate Professor, Department of Microbiology, DRPGMC Kangra at Tanda.
}

Corresponding Author: Aditya Rana

\begin{abstract}
Introduction: Emerging resistance in microorganisms is a matter of great concern in health care setups. Bacterial isolate and AMR pattern changes from place to place and time to time. Unprofessional use of antibiotics has resulted in an increasing burden of antibiotic resistance. This study focused over the aerobic bacteriological profile and antibiotic resistance pattern in pus isolates.

Materials and Methods: A retrospective study was carried out from June, 2020 to May 2021. 1174 pus samples collected during the study period were included. The samples were cultured on Blood and MacConkey agar. After aerobic incubation at $37^{\circ} \mathrm{C}$ for $18-24 \mathrm{hrs}$, organisms were identified by biochemical reactions, gram staining and antibiotic susceptibility was tested by Kirby Bauer disc diffusion method.
\end{abstract}

Result: Among the total 1174 pus samples, 712 $(60.6 \%)$ were male and $462(39.3 \%)$ were females. 857(72.9\%) samples showed positive results. Among them, Staphylococcus aureus was the most common isolate followed by Escherichia coli, Pseudomonas spp. and Klebsiella spp. The sensitivity of Staphylococcus aureus was highest with Vancomycin and Linezolid, whereas Enterobacterales and Pseudomonas were sensitive with Piperacillin tazobactam.

Conclusion: Increasing resistance always poses a challenge in treating infections. The development of resistant strains of pathogens can be limited by the judicious use of antibiotics. This study shows the infecting bacterial isolates and their antibiogram from this area.

Key words: Pus, antimicrobial resistance, bacterial isolates

\section{INTRODUCTION}

In developing countries infectious disease remains the most common cause of morbidity, mortality, medical and financial burden. Surgical procedure, trauma, burns, diseases, nutrition and others leads to microbial contamination results infection [1]. Surgical wound infections are the second most common cause of wound infections [2]. As wound infections are mainly health care associated and the infecting pathogens differ from place to place and time to time [3]. Nowadays antimicrobial resistance is a major public health concern in human medicine both in the community and in hospitals [4]. Inappropriate use of antibiotics in health setups has resulted in increased burden of antimicrobial resistance [5].

Exact causative agents of wound infection and appropriated AMR pattern has proven helpful in the selection of appropriate antimicrobial therapy [6]. Therefore, the present study aimed to evaluate the profile of aerobic pyogenic 
bacteria in our area along with their susceptibility to antimicrobial agents.

\section{MATERIAL AND METHOD}

Pus samples were received in the Department of Microbiology from in and outpatients departments of DRPGMC, Kangra at Tanda, Himachal Pradesh over a period of 1 years from June 2020 to May 2021. Pus samples were collected on sterile swabs and in sterile syringes. After collection samples were transported to Microbiology laboratory.

These samples were processed on blood agar, and MacConkey agar media and incubated at $37^{\circ} \mathrm{C}$ under aerobic conditions for 18-24 hours. The organisms were identified by biochemical reactions and Gram stain as per standard operative procedures. Kirby Bauer's Disk Diffusion method was used to test antimicrobial susceptibility and interpreted by Clinical Laboratory Standard Institution (CLSI) guidelines.[8] Standard Hi media antibiotics discs like Penicillin, Vancomycin, Gentamicin, Ciprofloxacin, Clindamycin, Azithromycin, Cefoxitin were used for Gram positive bacteria. Piperacillin, Ceftazidime, Gentamicin, Cotrimoxazole, Ticarcillin, Imipenem and Cephalothin were used for Gram negative bacteria.

\section{RESULTS}

received in the Department of Microbiology, DRPGMC Kangra at Tanda, Himachal Pradesh. Out of 1174 samples 712 $(60.6 \%)$ were males and 462(39.3\%) were females.

857(72.9\%) pus samples showed positive bacterial growth whereas 317 samples showed no growth, fungal growth and contaminants from skin.153(17.9\%) samples were from OPD, 687(80.1\%)were from IPD and 17(2\%) from ICU's .Based on gram staining gram negative bacteria were in predominance with $498(58.1 \%)$ and $359(41.8 \%)$ gram positive bacteria. In gram negative bacteria most common was Escherichia coli 142(28.51\%), followed by Pseudomonas spp. 126(25.3\%), Klebsiella spp $117(23.4 \%)$ and least common was Providencia spp. 2(0.4\%). In gram positive bacteria Staphylococcus aureus was in predominance $319(88.8 \%)$ followed by CONS 27(7.5\%) Enterococcus spp. $15(4.1 \%)$ and least was beta hemolytic streptococcus $\quad 8(2.2 \%)$ Overall Staphylococcus aureus 319(37.2\%) was most frequently isolated from pus samples followed by Escherichia coli 142(16.5\%). Predominance of staphylococcus aureus was also seen in OPD (45.5\%), IPD (32.9\%) and ICU $(50 \%)$ pus samples.

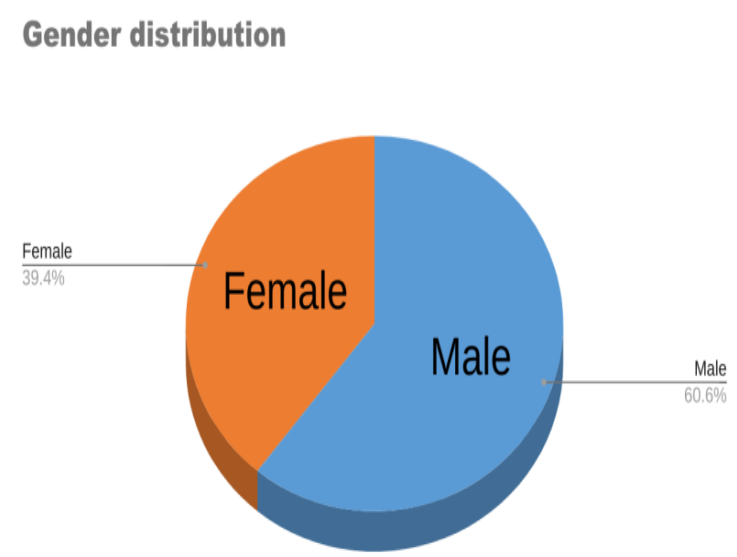

Figure 1: Gender distribution.

\section{Distribution in Hospital}

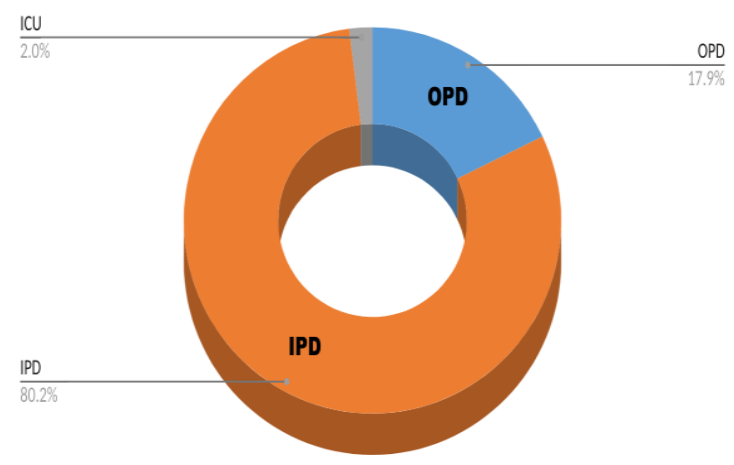

Figure 2: Distribution of pus samples as per OPD, IPD \& ICU 
Aditya Rana et.al. Aerobic bacterial isolates and their antibiotic susceptibility patterns of pus samples at tertiary healthcare center of Northern India.

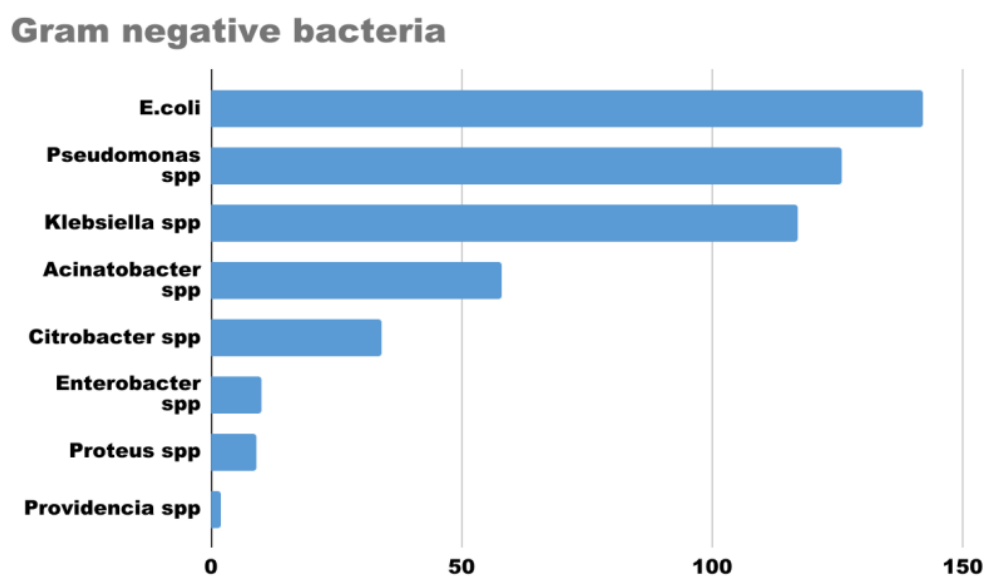

Figure 3: Distribution of Gram negative bacteria in pus samples.

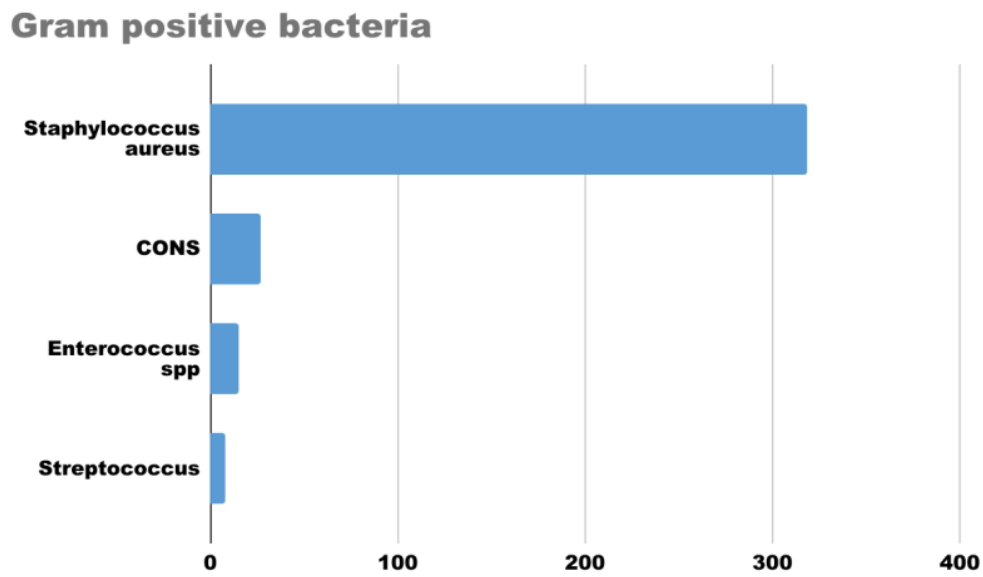

Figure 4: Distribution of Gram positive bacteria in pus

Table 1: Antibiotic resistance percentage in Gram negative isolates

\begin{tabular}{|l|l|l|l|}
\hline & $\begin{array}{l}\text { Escherichia } \\
\text { coli (n=142) }\end{array}$ & $\begin{array}{l}\text { Klebsiella } \\
\text { spp } \\
\text { (n=117) }\end{array}$ & $\begin{array}{l}\text { Pseudomonas } \\
\text { spp (n=126) }\end{array}$ \\
\hline Cefazolin & $70.4 \%$ & $41 \%$ & NA \\
\hline Ceftazidime & $21.1 \%$ & $34.1 \%$ & $21.4 \%$ \\
\hline Gentamicin & $50 \%$ & $55.5 \%$ & $25.3 \%$ \\
\hline Amoxyclav & $23 \%$ & $50 \%$ & NA \\
\hline $\begin{array}{l}\text { Ampicillin } \\
\text { sulbactam }\end{array}$ & $26.7 \%$ & $35.8 \%$ & $50 \%$ \\
\hline Amikacin & $14 \%$ & $29.9 \%$ & $26.1 \%$ \\
\hline Ciprofloxacin & $54.9 \%$ & $45.2 \%$ & $26.9 \%$ \\
\hline Ceftriaxone & $84.5 \%$ & $70 \%$ & $54.7 \%$ \\
\hline $\begin{array}{l}\text { Piperacillin } \\
\text { tazobactam }\end{array}$ & $40.8 \%$ & $29 \%$ & $19.8 \%$ \\
\hline Imipenem & $42.2 \%$ & $50 \%$ & $48.4 \%$ \\
\hline
\end{tabular}

Table 2: Antibiotic resistance percentage in Gram positive isolates

\begin{tabular}{|l|l|l|}
\hline & $\begin{array}{l}\text { Staphylococcus aureus } \\
(\mathbf{n = 3 1 9})\end{array}$ & $\begin{array}{l}\text { CONS } \\
(\mathbf{n = 2 7})\end{array}$ \\
\hline Penicillin & $81.8 \%$ & $88.8 \%$ \\
\hline Erythromycin & $36 \%$ & $40.7 \%$ \\
\hline Clindamycin & $25 \%$ & $14.8 \%$ \\
\hline Vancomycin & $4.7 \%$ & $3.7 \%$ \\
\hline Linezolid & $2.5 \%$ & $0 \%$ \\
\hline Cefoxitin & $36.36 \%$ & NA \\
\hline Cotrimoxazole & $41 \%$ & $59.2 \%$ \\
\hline
\end{tabular}

Antimicrobial susceptibility patterns for most common pus isolates were carried out. Resistance percentages for various antibiotics are shown in table 1 and table 2 .

\section{DISCUSSION}

In our study males were in predominance to females with male to female ratio of 1.5:1. Comparable results were found in study by Mudassar et al which showed predominance of males.[8]

Majority of the samples in our study were from in patient department similarly Pilli et al in their study showed majority of pus isolates from IPD. [9]

This study revealed S. aureus to be the most commonly occurring pathogen $(37.2 \%)$ in pus samples. Similar results were seen in study by Mantravadi et al and Mahmood et al with high prevalence of S.aureus. [10,11]. This could be due to 
Staphylococcus aureus being normal flora of the skin and is usually associated with pyogenic infections.[12]

E. coli $(28.51 \%)$, Pseudomonas spp. $(25.3 \%)$ followed by Klebsiella spp. $(23.4 \%)$ was the most common GNB isolated from the pus samples in our study. Similarly in study by Mantravadi et al showed E.coli in majority.[10]

S. aureus showed maximum resistance to penicillin with $81.8 \%$ resistance followed by cotrimoxazole $(41 \%)$ and erythromycin (36\%). Similarly high antibiotic resistance was seen by S. aureus to penicillin ( $84.5 \%$ ) in study by Mantravadi et al.[10] Highest sensitivity was shown by drugs like linezolid and vancomycin. MRSA was $116(36.36 \%)$ of total S.aureus isolates.

E. Coli showed maximum resistance to ceftriaxone $(84.5 \%)$, cefazolin $(70.4 \%)$ and ciprofloxacin(54.9\%). Mudassar et al in their study revealed similar increase in resistance in third generation cephalosporins and fluoroquinolones [8] Klebsiella spp. showed resistance toward ceftriaxone $(70 \%)$ followed by gentamicin (55.5\%) Mantravadi et al in their study had similarity with our results [10]. Pseudomonas was most resistant to ceftriaxone (54.7\%), Ampicillin sulbactam $(50 \%)$ and Imipenem (48.4\%). Piperacillin tazobactam showed best susceptibility in gram negative isolates. Wadekar et al had comparable results with susceptibility of Piperacillin tazobactam in gram negative isolates [13].

Good knowledge of the bacteriology of an infection and the antimicrobial susceptibility testing of microorganisms implicated could make drug selection in antimicrobial chemotherapy more rational.

\section{CONCLUSION}

Increasing resistance always poses a challenge in treating infections. The development of resistant strains of pathogens can be limited by the judicious use of antibiotics. Over the counter availability of antibiotics is a matter of concern. Inappropriate selection of antibiotics allows microbes to survive treatment and lead to resistance.

Hence it becomes essential to know the prevalent profile and sensitivity pattern to guide the clinicians to start the empirical treatment.

\section{Acknowledgement: None}

Conflict of Interest: None

\section{Source of Funding: None}

\section{REFERENCES}

1. Howard RJ, Ravitch MM, Steichen FM: Host against Infections. Current Problems in Surgery. New Eng J Med 1980, 12:18231830.

2. Burke JP. Infection control - a problem for patient safety. N Engl J Med. 2003 Feb 13;348(7):651-6.

3. Ogunsola FT, Oduyebo $\mathrm{O}$, Iregbu $\mathrm{KC}$, Coker AD, Adetunji A: A review of nosocomial infections at LUTH; problems and strategies. J Nigerian Infection Control Association 1998, 1:213-217.

4. Sabir, R., Alvi, S.F.D. and Fawwad, A. Antimicrobial susceptibility pattern of aerobic microbial isolates in a clinical laboratory in Karachi-Pakistan. Pakistan journal of medical sciences, 2013;29:851,

5. Kumar AR. Antimicrobial sensitivity pattern of Klebsiella pneumonia isolated from pus from tertiary care hospital and issues related to the rational selection of antimicrobials. J. Chem. Pharm. Res, 2013; 5(11): 326-331.

6. Adebayor OS, Deboye OK, Emiola AR: Wound Infections in two Health Institutions in IIE-Ife, Nigeria: Results of a cohort study. Osto/Wound Manag 2003, 49:52-57.

7. Clinical and Laboratory Standards Institute, Performance Standards for Antimicrobial Susceptibility Testing: Twenty Second Informational Supplement, CLSI Document M100-S22, CLSI, Wayne, Pa, USA, 2012.

8. Mudassar S, Khan SW, Ali M, Mahmood F. Aerobic bacteriological profile and antimicrobial susceptibility pattern of pus isolates in a teaching hospital, Lahore, Pakistan. Int J Contemp Med Res [IJCMR] [Internet]. 2018;5(4). 
Aditya Rana et.al. Aerobic bacterial isolates and their antibiotic susceptibility patterns of pus samples at tertiary healthcare center of Northern India.

9. Kumari P,Dusi R, Padmaja,Mohan N, Lakshmi P. A Cumulative Antibiogram for a Period of one year and its Analysis in a Tertiary Care Hospital. J med sci clin res [Internet]. 2019;7(6).

10. Mantravadi H, Chinthaparthi M, Shravani V. Aerobic isolates in pus and their antibiotic sensitivity pattern: a study conducted in a teaching hospital in Andhra Pradesh. Int $\mathbf{J}$ Med Sci Public Health. 2015;4(8):1076.

11. Mahmood A. Bacteriology of surgical site infections and antibiotic susceptibility pattern of the isolates at a tertiary care hospital in Karachi. J Pak Med Assoc 2000;50:256-9.

12. Sultana S, Mawla N, Kawser S, Akhtar N, Ali MK. Current Microbial Isolates from
Wound Swab and Their Susceptibility Pattern in a Private Medical College Hospital in Dhaka city. Delta Med Col J. 2015;3(1):25-30.

13. Sathish, D Wadekar M, Jayashree, Pooja. Bacteriological profile of pus samples and their antibiotic susceptibility pattern. Ind J Microbiol Res. 2020;7(1):43-7.

How to cite this article: Rana A, Gupta V, Jaryal $\mathrm{SC}$ et.al. Aerobic bacterial isolates and their antibiotic susceptibility patterns of pus samples at tertiary healthcare center of Northern India. International Journal of Research and Review. 2021; 8(9): 247-251. DOI: https://doi.org/10. 52403/ijrr.20210934 